•综述・

\title{
杜鹃花属植物的可育性研究进展
}

\author{
庄 平 $^{*}$ \\ (中国科学院植物研究所华西亚高山植物园, 四川都江堰 611830)
}

\begin{abstract}
摘要: 结合作者近年来的工作, 总结了国内外有关杜鹃花属(Rhododendron)植物可育性研究的成果和进展, 旨在 为相关研究者和技术人员提供参考。(1)杜鹃花属的杜鹃亚属(subgen. Rhododendron)和羊踯躅亚属(subgen. Pentanthera) 中存在多倍化现象, 甚至存在同一物种有多种倍性。(2)在自然授粉条件下, 除了常见种内杂交及自交 情形外, 常绿杜鹃亚属(subgen. Hymenanthes)、杜鹃亚属和映山红亚属(subgen. Tsutsusi)内种间杂交十分普遍，也有 跨亚组之间的自然杂交案例。(3)杜鹃花属植物中自交亲和(self compatibility, SC)与自交不亲和(self incompatibility, SI)现象并存, 云锦杜鹃亚组(subsect. Fortunea) 兼具自交败育到高可育性的所有类型, 而在映山红亚属与马银花亚 属(subgen. Azaleastrum)中自交不亲和现象则更为常见。通常自交被认为是杜鹃花物种的被动适应, 但对于一些在 极端气候条件下分布的局域种而言, 则可能是一种主动响应。(4)不同分类等级(亚属、组和亚组)间的人工杂交研 究表明, 杂交亲和性或可育性与双亲的系统发育关系及染色体倍性具有明显的关联, 并反映在发育阶段和各项亲 和力指标的变化之中。常绿杜鹃亚属与杜鹃亚属间的远缘杂交相对比较容易, 常绿杜鹃亚属与映山红亚属间、映 山红亚属与杜鹃亚属的正反交、映山红亚属与羊踯躅亚属的正交以及常绿杜鹃亚属与羊踯躅亚属的正交、马银花 亚属与杜鹃亚属正交等也有亲和的案例。(5)自交不亲和亲本的介入可大幅度增加种间杂交的不育比率, 并导致其 由双向可育到单向不育再到双向不育方向发展。
\end{abstract}

关键词：杜鹃花属；多倍体；传粉生物学；自交；杂交；亲和性；可育性

\section{Progress on the fertility of Rhododendron}

\author{
Ping Zhuang* \\ West China Subalpine Botanical Garden, Institute of Botany, Chinese Academy of Sciences, Dujiangyan, Sichuan 611830
}

\begin{abstract}
To provide a reference for researchers, achievements and progress in recent years on the fertility of Rhododendron in China and abroad were summarized. (1) There are polyploidy in subgen. Rhododendron and subgen. Pentanthera, and even various ploidy in the same species. (2) Under natural pollination, in addition to the common intra-specific cross- and self-fertilization, inter-specific cross-fertilization was also widespread in subgen. Hymenanthes, subgen. Rhododendron and subgen. Tsutsusi. There were also some cases of inter-subsection cross. (3) Self compatibility (SC) and self incompatibility (SI) simultaneous exist in Rhododendron. Subsect. Fortunea shows all types from self sterile to high fertility. Self incompatibility often occurs in subgen. Tsutsusi and subgen. Azaleastrum and although self-fertilization is usually considered to be a passive adaptation, it could be an active response to the adverse environmental conditions for a few local species. (4) Through artificial crosses between different taxa (subgenera, sections and subsections), the inter-specific crossability was obviously relevant to the relationship of phylogenetic development and chromosomal ploidy of parents. This was reflected in the changes of indices of compatibility in different phases of development and was discovered that hybridization was easier between distant subgen. Hymenanthes and subgen. Rhododendron. There were also some cases of compatibility such as the reciprocal crosses between subgen. Hymenanthes and subgen. Tsutsusi, subgen. Tsutsusi and subgen. Rhododendron as well as the unidirectional compatibility between subgen. Tsutsusi and subgen. Pentanthera, subgen. Hymenanthes and subgen. Pentanthera, subgen. Azaleastrum and subgen. Rhododendron. (5) It leads to increases in the fertility and development from bidirectional fertility to unidirectional sterility and then
\end{abstract}


bidirectional sterility in inter-specific cross as SI parents get involved.

Key words: Rhododendron; polyploid; pollination biology; self-fertilization; hybridization; compatibility; fertility

杜鹃花属(Rhododendron)为中国最大的木本植 物属, 全世界约 1,000 种, 分为 8 个亚属(Chamberlain et al, 1996)。中国有杜鹃花属植物571种(特有种409 种), 分属6亚属10组49亚组(Fang et al, 2005), 其中 常绿杜鹃亚属(subgen. Hymenanthes, 259种)和杜鹃 亚属(subgen. Rhododendron, 184种)之和分别占全球 总种数的 $44.3 \%$ 和我国种数的 $77.6 \%$ 。川西、滇西和 藏东南地区是该属植物的现代分布中心和分化中 心。马来西亚一巴布亚新几内亚热带山地是杜鹃花 属的另一个分布中心, 其种类达 300 种左右, 主要 为杜鹃亚属越桔杜鹃组(sect. Vireya)物种(闵天禄和 方瑞征, 1979; 方瑞征和闵天禄, 1995)。

杜鹃花属植物自起源以来已经历了数千万年 的进化历程(闵天禄和方瑞征, 1979，1990)。其类群 分化与分布格局(尤其是在现代分布中心区)与起源 地温润气候、第三纪渐新世以来青藏高原快速抬升 与东亚季风的形成与加强, 以及第四纪多次冰川的 进退等地质历史事件密切关联(方瑞征和闵天禄, 1981, 庄平, 2012; 庄平等, 2013); 而东南亚岛屿热 带山地气候条件下激烈的物种竞争, 使得杜鹃花属 植物出现了暴发式的物种分化(方瑞征和闵天禄, 1995)。在我国喜马拉雅山地及横断山区杜鹃亚属与 常绿杜鹃亚属和东南亚热带岛屿越桔杜鹃的物种 多样化分化(Brown et al, 2006), 共同表明杜鹃花属 是一个仍处于蓬勃发展过程中的类群。最近 Shrestha等(2018)通过相关分子生物学研究发现, 热 带与亚热带山地不但是杜鹃花属的多样性与特有 性的热点区域，也是该属物种多样性的摇篮。

植物的变异来源包括基因突变、重组和染色体 倍性变化。作为世界著名的观赏植物, 杜鹃花的生 殖生物学尤其是繁殖生物学中的可育性研究显得 十分重要。近百年来, 随着遗传学的日臻完善和现 代分子生物学的发展, 杂交育种的理论和技术也取 得了长足进展, 国外杜鹃花新品种培育已经从杂交 育种、多倍体育种逐渐步入分子育种的阶段, 公开 注册的杜鹃花品种已有2.5万个(兰熙等, 2012)。相比 之下, 我国作为杜鹃花属种类最多的国家, 在培育 杜鹃花新品种的数量和水平上, 至少落后于发达国
家20年以上(吴荭等, 2013)。据刘晓青等(2010)报道, 我国利用的栽培杜鹃品种只有 400 个左右, 其中正 式注册的新品种仅 34 个(兰熙等, 2012; 王定跃等, 2012)。

因此，笔者期望通过梳理近代有关杜鹃花属植 物可育性研究的主要进展与成果, 并对作者近年来 在相关领域的一些研究(庄平, 2017a, b, 2018a, b, c, d, e, 2019)进行总结, 以期为我国杜鹃花属植物的 可育性研究和实践提供参考。

\section{染色体与分子系统学}

有关杜鹃花染色体的研究已经历了 80 余年，但 很多物种的染色体资料至今仍是空白。Sax (1930) 测定了 23 个杜鹃花样本的染色体数目, 其中包括产 自于北美、欧洲、日本及朝鲜的 16 个种，首次提出 杜鹃花属植物的染色体基数 $\mathrm{N}=13$, 并发现原产北 美的 R. canadense 和 $R$. calendulaceum 为四倍体; Ammal (1950)对杜鹃花类群开展了更加广泛和深入 的研究, 指出杜鹃花的多倍体现象出现在有鳞类 (杜鹃亚属)和一些羊蹶踢亚属(subgen. Pentanthera) 的类群中, 二倍体 $2 \mathrm{~N}=26$, 最高倍性为十二倍体 $2 \mathrm{~N}=12 \mathrm{x}=156$ 。其中杜鹃亚属中的苍白杜鹃亚组 (subsect. Glauca)、鳞腺杜鹃亚组(subsect. Lepidota) 和怒江杜鹃亚组(subsect. Saluenensia)为二倍体和 四倍体物种, 高山杜鹃亚组(subsect. Lapponica)与 三花杜鹃亚组(subsect. Triflora)则有倍性2、4、6, 有鳞大花亚组(subsect. Maddenia)的倍性有2、4、6、 12, 亮鳞杜鹃亚组(subsect. Heliolepida)为4、6、8, 朱 砂杜鹃亚组(subsect. Cinnabarina)为4; 羊蹶躅亚属 羊蹶躅组的 R. luteum 和蓄薇杜鹃组(sect. Rhodora) 的 $R$. canadense均为四倍体。Ruth等(2000)对杜鹃亚 属越桔杜鹃组 7 个亚组中的 27 个种及 1 个亚组间杂 种进行了染色体观察, 发现该组所有研究的物种均 为 $2 \mathrm{~N}=26$ 。高连明等(2005)研究了马银花亚属 (subgen. Azaleastrum)中马银花组(sect. Azaleastrum) 和长苾杜鹃组(sect. Choniastrum)的6种1变种的染 色体数目, 发现该亚属物种为二倍体 $(2 \mathrm{~N}=26)$ 。 Schepper等(2001)研究的 6 种映山红亚属 (subgen. 
Tsutsusi)自然种均为二倍体, 而人工品种中有三倍 体和四倍体。据美国杜鹃花协会网上 (www.rhododendron.org) 公布的资料，已查明为多 倍体的杜鹃花原始种还有: 杜鹃亚属有鳞大花亚组 的线蕶杜鹃 (R. crassum)(6、4)、隐脉杜鹃 (R. maddenii)(6、4)、R. manipurense (6、4)、高山杜鹃亚组 的光柱杜鹃 (R. flavidum) (4、2)、高山杜鹃 $(R$. lapponicum) (4、2)、多色杜鹃 $(R$. rupicola) (4、2)、 怒江杜鹃亚组的美被杜鹃( $R$. calostrotum) (4、2)、 亮鳞杜鹃亚组的红棕杜鹃 (R. rubiginosum) (6、4), 羊蹶躅亚属的 R. occidentale (6)、R. chameunum (4、 2 )和 $R$. lysolepis (4、2)。其中绝大多数种类为杜鹃亚 属成分, 其倍性不固定且从植物外部形态上很难 区别。

Ammal等(1950)注意到, 多倍体现象主要出现 在有鳞类杜鹃中, 主要分布在滇西、川西和喜马拉 雅亚高山和高山区, 因而认为杜鹃花属植物染色体 的倍性变化与其由低海拔向高海拔的进化适应有 关。而在北美与欧洲, 杜鹃花多倍体发生在羊踯躅 亚属这类落叶杜鹃类群中, 其倍性进化也可能与向 山地演化和北半球大陆冰川的进退存在一些联系。

Kurashige等(2001)基于 matK和trnK序列对杜鹃 花属的8亚属51个种的分子系统学研究表明, 杜鹃 花属是一个并系类群, 常绿杜鹃亚属、杜鹃亚属和 映山红亚属为单系, 而马银花亚属和羊踯躅亚属为 多系。Goetsch等(2005)基于核基因序列RPB2对杜鹃 花属 87 个种的分析表明, 除叶状苞亚属(subgen. Therorhodion)外, 杜鹃花属可分为 3 个主要分支, 支 持马银花亚属和羊蹶躅亚属为多系类群。Gillian等 (2006)的研究表明, 杜鹃组(sect. Rhododendron)和 越桔杜鹃组均为多系。Milne等(2010)利用叶绿体 DNA标记对常绿杜鹃亚属的研究表明, 常绿杜鹃亚 属可分为两个分支, 其中一个主要分布在中国-喜 马拉雅的分支包含了一组多样化且古老的成分。

Liu等(2012)利用ISSR和RAPD标记证实了我国 长白山地区的牛皮杜鹃( R. aureum) 具有高的遗传多 样性。Huang等(2011)通过分析台湾高山分布的 $R$. pseudochrysanthum 的叶绿体与核DNA研究了该种 的遗传多样性水平。Wolf等(2004)利用AFLP研究了 分布于比利牛斯和阿尔卑斯山海拔1,600-2,000 m 的 R. ferrugineum的遗传与地理距离的关系, 发现沿 海拔梯度遗传距离与空间距离呈正相关, 从而提出
了小尺度情形下距离隔离可通过种子扩散限制基 因流。Jose等(2002)通过研究欧洲伊比利亚半岛南部 分布的 R. ponticum, 发现其缺乏幼龄个体, 认为该 植物是当地一个残遗的复合种群(metapopulation)。

\section{传粉生物学}

在自然条件下, 有性繁殖是杜鹃花属植物最主 要的繁殖方式, 虽然天然无性繁殖也有一些报道 (Pornon et al, 1997; Karlsson \& Jacobson, 2001; Stout et al, 2006), 但尚未发现无融合生殖现象(张敬丽等, 2007)。杜鹃花为虫媒植物, 在天然条件下的自然授 粉包括了自交(同株或同基因型个体间的交配)、种 内杂交(同种不同基因型个体之间的交配)和种间杂 交(如相同亚组内和不同亚组间的种间个体交配), 但未见不同亚属间种间自然杂交的报道。

Escaravage和Wagner (2004)研究了高山杜鹃的 传粉媒介, 认为最频繁和最有效的传粉昆虫是蜜蜂 和熊蜂, 家蝇也具有较高的访问率, 而蝶类传粉的 效果可以忽略, 食蚜蝇、蚂蚁与甲壳虫对传粉没有 功效。Akiko等(2008)和Gaku等(2011)的研究也证实 了熊蜂(Bombus ardens, B. honshuensis)是杜鹃花的 重要传粉媒介。Griffin和Eckert (2003)认为, 育性与 工蜂的活动期密切关联, 早期开花的种群缺乏工蜂 活动, 自交率高, 败育率也高。更早些时候Williams 等(1990)转述了1974年Leppik在北美的研究结果, 即 R. periclymeniodes的访问者主要是野蜂(访问频 率 $85 \%$ ), 而熊蜂仅仅是偶尔光顾, 并提到Stevens等 学者认为在越桔杜鹃类群集中分布的东南亚热带 山地, 传粉媒介包括鸟、蝙蝠、蝴蝶、蛾、蜜蜂、 螨类等。Ng和Corlett (2000)注意到, 中国香港地区6 种分别源于映山红亚属和马银花亚属杜鹃花的传 粉媒介中还包括多种木晶蜡属(Xylocopa) 昆虫。张 敬丽等(2007)发现中华蜜蜂(Apis cerana)是马缨杜 鹃(R. delavayi)、迷人杜鹃(R. agastum)、露珠杜鹃 $(R$. irroratum) 和大白杜鹃 ( $R$. decorum) 等4种常绿杜鹃 的共有传粉媒介, 而分舌蜂(Coalletes sp.)则为迷人 杜鹃与露珠杜鹃的专有传粉媒介。Huang等(2017) 对15种分布于东喜马拉雅的杜鹃花的研究发现, 鸟 类可能是其中 10 种杜鹃花植物的有效传粉媒介, 从 而认为当地的杜鹃花区系受益于这些鸟类的演化。 $\mathrm{Li}$ 等 (2018) 发现大树杜鹃 (R. protistum var. giganteum)的传粉动物包括熊蜂、太阳鸟和啄花鸟, 
并指出该种红色的花可能具备鸟媒植物的特征。 Song等(2019)发现13种杜鹃花的传粉媒介包括鸟 类、蝶类、蛾类等多种。

研究表明, 部分杜鹃花物种的自交与异交保持 着微妙的平衡。Akira (2010)利用多个位点对常绿杜 鹃亚属短果杜鹃 (R. brachycarpum)后代自然授粉的 适合度进行了研究, 结果表明该种个体间的自交水 平决定着其后代的适合度, 亲本间的遗传相似程度 决定着后代的自交衰退度。同为常绿杜鹃亚组的牛 皮杜鹃也可自花授粉, 但在有昆虫媒介的条件下, 其坐果率提高，延迟开花有利于异交授粉(Gaku, 1993), 其败育与自交和远缘杂交有关(Gaku \& Kudo, 2011)。

研究显示自然授粉可产生自然杂交后代, 并在 有限区域生存。Tagane (2008)发现映山红组生于日 本海滨生境的圆叶杜鹃( R. eriocarpum)和河岸生境 的臬月杜鹃 $(R$. indicum)的杂交后代出现在海滨生 境中, 并形成了较稳定的居群。R. $\times$ sochadzeae 是土 耳其北部常见的常绿杜鹃亚属的自然杂交后代, 其 双亲为同亚组的 $R$. ponticum 和高加索杜鹃 $(R$. caucasicum) (Milne et al, 2003)。张敬丽等(2007)通 过去雄不套袋的自由授粉实验发现, 马缨杜鹃、迷 人杜鹃、露珠杜鹃和大白杜鹃均能种间杂交结实。 Zhang等(2007)通过形态特征、核DNA序列ITS、叶 绿体DNA trnL-F分析, 指出常绿杜鹃亚属中的迷人 杜鹃(露珠杜鹃亚组 subsect. Irrorata)是同亚属马缨 杜鹃(树形杜鹃亚组subsect. Arborea)与大白杜鹃(云 锦杜鹃亚组 subsect. Fortunea)的天然杂交后代。而 Zha等(2010)则认为迷人杜鹃是马缨杜鹃与露珠杜 鹃的杂交后代。Ma等 $(2010,2016)$ 也发现, 该亚属中 的蓝果杜鹃 (R. cyanocarpum)(蜜腺杜鹃亚组subsect. Thomsonia)与马缨杜鹃存在自然杂交现象, 能进行 不对称的双向交配, 并指出前合子期生殖障碍比后 合子期生殖障碍对成种的贡献更大。Yan等(2017, 2018) 研究了杜鹃亚属糙叶杜鹃亚组 (subsect. Scabrifolia) 粉红爆杖花 $(R . \times$ duclouxii) 的遗传结构 与繁殖生物学, 发现该类群是碎米花 (R. spiciferum) 和爆仗花 ( $R$. spinuliferum)之间的自然杂种, 亲本种 间双向杂交，且呈现不对称基因渐渗，并进一步指 出不完全生殖隔离会促进杂种形成及其持续存在, 但可延迟通过杂交形成物种。

近年来, 庄平(2017a)在四川都江堰龙池基地
(海拔 $1,700 \mathrm{~m}$ )及玉堂基地(海拔700 m)和峨眉山生 物试验站(海拔805 m) 对5亚属15亚组37种杜鹃花开 展了为期 4 年的自然授粉研究, 并以绿苗率为主要 指标, 绿苗系数、坐果率和单位可育种子数为辅助 指标，初步揭示了在迁地保育条件下杜鹃花属植物 自然授粉的育性适应及其特征。结果表明，除仅 1 株开花的黄花杜鹃(R. lutescens)未形成种子外, 受 试的其他 36 种杜鹃花均能在其保育地点不同程度 地完成从种子(幼苗)到种子的生命循环。其中高可 育型24种、可育型11种、弱育型1种，有24种出现不 同程度的败育现象，推测其原因可能为不同程度的 自交或是花期重叠的同亚组内到不同亚组间异种 自然交配所引起的遗传不适，也可能与迁地保育区 的媒介变化有关，这种现象在一些开花个体有限的 种类中尤为突出(Richard et al, 2003), 因此认为保 证最小存活种群(the minimum viable population, MVP)对于该属植物迁地保育至关重要。

\section{3 自交}

自交被定义为同一个体或相同基因型的不同 个体之间的交配。有关研究往往需要借助人工套袋, 通过同株或同花人工授粉实验来加以证明。许多学 者都认为杜鹃花属植物的大多数种类为自交亲和 (self compatibility, SC) (Williams et al, 1990; Rouse et al, 1993)。自交亲和或具有一定亲和力的杜鹃花 属植物有: 常绿杜鹃亚组中的短果杜鹃 (Akira, 2010)、牛皮杜鹃(Gaku, 1993)、R. ponticum (Jose et al, 2002)、露珠杜鹃(张敬丽等, 2007), 杜鹃亚属的木兰 杜 鹃 (R. uttallii) (Palser，1989)、R. ferrugineum (Escaravage \& Wagner, 2004), 羊踯躅亚属的 $R$. canadense (Nathannel et al, 2006)。而自交不亲和或 亲和力弱的种类包括异荵杜鹃亚属 (subgen. Mumeazalea)的R. semibarbatum (Akiko et al, 2008); 映山红亚属的丁香杜鹃 (R. farrerae)、映山红 $(R$. simsii)、R. simiarum (Ng \& Corlett, 2000)以及马银花 亚属的香港马银花 $(R$. hongkongense)、R. moulmainense、 R. championiae; 杜鹃亚属越桔杜鹃组中的 $R$. championce, R. amamiense等(Williams et al, 1990; Rouse et al, 1993)以及常绿杜鹃亚属中的马缨杜鹃、 迷人杜鹃和大白杜鹃等(张敬丽等, 2007)。

Williams等(1990)通过对 R. championce的研究 发现, 自交不亲和主要源于同型致死基因(lethal 
gene)作用所导致的合子后败育 (post-zygotic abortion)。Akiko等(2008)对分布在日本的R. semibarbatum的研究发现, 该种雄荵先熟(protandrous), 为 合子前隔离, 需要外部传粉者介入才能结实。Hirao (2006) 比较R. aureum花期昆虫访问、花粉散布、交 配模式、有性繁殖的早迟变化, 认为花季末期由于 自交率增加，种子产量减少。而Escaravage和Wagner (2004)通过对R. ferrugineum的研究发现, 该种自交 亲和系数(self-compatibility index)高达0.95-0.97。

庄平(2017b)对5亚属13亚组32种在迁地保育条 件下的自交可育性的阶段研究结果表明，自交可育 与不育是杜鹃花属植物有性生殖中的两个并存现 象, 自交可育型物种或多于不育型。在受试的32种 杜鹃花中(其中 27 种的自交育性为首次报道), 自交 不育型 10 种、弱可育型5种、可育型7种、高可育型 10种; 并通过与自然授粉有关育性指标的比较发现, 不同种类的自交可育性指标有大幅度降低及增高 两种截然不同的现象。其中毛肋杜鹃(R.augustinii)、 峨嵋银叶杜鹃(R. argyrophyllum subsp. omeiense)、大 王杜鹃( $R$. rex)、云南杜鹃( $R$. yunnanense)、繁花杜 鹃( $R$. floribundum) 和宝兴杜鹃 $(R$. moupinense)等6个 种在自交条件下的单位可育种子数量比自然授粉 的相应值增加了 $3.7 \%-89.8 \%$, 而且前 4 种植物的绿 苗率也提高了 $16.6 \%-42.7 \%$, 从而认为自交可能是 部分杜鹃花属植物的适应策略, 或者对不利环境 (如阴湿等极端环境)和媒介条件的主动响应。云锦 杜鹃亚组(subsect. Fortunea)含有包括从自交不育到 高可育所有类型的物种, 然而在映山红亚属、马银 花亚属及羊距躅亚属中，自交不亲和则更为常见。 分布区域的生长环境对物种的长期直接作用或通 过影响传粉媒介的间接作用可能是最终塑造该属 植物自交育性多样化的驱动力。鉴于自交不亲和可 以发生在授粉后的各个阶段, 而且不能坐果占不育 的比率达 $80 \%$, 笔者认为合子后自交败育理论 (Williams et al, 1990)不能完全解释这一现象。

\section{杂交}

杂交的概念包括同一种内不同的基因型个体 之间和不同物种之间的交配。在传授粉生物学一节 中, 已介绍了杜鹃花属植物普遍存在自然杂交现象, 但迄今为止尚未见有跨亚属间的自然杂交报道。 Williams等(1990)在总结杜鹃花属植物种间杂交研
究时指出, 种间杂交出现从完全亲和到完全不亲和 的情况属于正常现象，而不亲和的现象可以表现为 从花粉不能在柱头上萌发一直到子代种子败育，包 含合子前不亲和与合子后败育。杜鹃花属种内杂交 和种间杂交在自然条件下普遍存在，本部分将重点 介绍人工种间杂交。

\section{1 种内杂交}

如前文所述，种内的自然杂交普遍存在，是杜 鹃花属的主要繁育方式。如张敬丽等(2007)通过同 种异株授粉和发芽实验证实，马缨杜鹃、迷人杜鹃、 露珠杜鹃和大白杜鹃的种内杂交均能获得很高的 结实率和种子发芽率。居群遗传多样性丰富且种内 杂交频繁可能是适应环境变化并保持种群延续的 基本策略(Levins, 1970), 这一理论也适合杜鹃花属 植物。

\section{2 种间杂交}

据Williams等(1990)和Rouse等(1993)报道，越 桔杜鹃组内的各亚组间和亚组内的物种间基本上 无杂交障碍，并育成了包括'Wattle Bird’、'Liberty' 等在内的十余个著名园艺杂交品种。越桔杜鹃组内 种间杂交的亲和力甚至可以简单地用亲本的雌荵 长度比(SLR值)来衡量。他们认为在 SLR $<0.2$ 或 SLR > 6时杂交不能成功, 随着SLR接近1.0时成功 率增加; 当SLR $<0.2$ 时, 短型花柱种的花粉管不能 抵达子房; 当SLR > 5-6时, 长型花柱种能深入子房 但很少观察到进入胚珠。因而，在越桔杜鹃组中的 全异花柱(disparate style)长度是杂交亲和性的限制 因素(Williams \& Rouse, 1988)。但除越桔杜鹃组外, 目前尚无证据支持杜鹃花属植物的其他类群中或 类群间的杂交也遵循此规律。

Rouse等(1993)认为，羊蹶躅亚属和映山红亚 属(被统称为Azalea类群)间杂交可以亲和，但通常 植株弱, 后代不能进入花期。有关常绿杜鹃亚属与 上述Azalea类群间杂交的资料非常圆乏，无鳞类杜 鹃与有鳞类杜鹃杂交通常存在生殖隔离障碍，难以 形成种子; 越桔杜鹃组与Azalea类群间杂交偶尔可 产生后代，但后代的花通常败育，如 $R$. retusum $\times R$. nudiflorum。杜鹃组植物作为父本与Azalea交配则可 产生有生活力的种子, 但幼苗贏弱, 通常在开花前 即死亡。Williams等(1990)也强调，尽管有鳞类与无 鳞类杜鹃杂交困难，但也有成功的例子，如 ‘Grierdal' (R. griersonianum $\times$ R. dalhousice $)$, 越桔 
杜鹃亚组的品种“Lord Walsely’与映山红亚属的杂 交等。

张长芹等(2002)报道的“朝晖”和 “红晕” 是常绿 杜鹃亚属亚组间的马缨杜鹃分别与大白杜鹃和露 珠杜鹃经人工杂交育成的新品种。并通过授粉实验 和坐果率的统计分析, 认为同亚属不同亚组间二倍 体之间杂交亲和力强, 如露珠杜鹃 $\times$ 马缨杜鹃、粗 柄杜鹃 $(R$. pachypodum $) \times$ 基毛杜鹃 $(R$. rigidum $)$ 的 坐果率分别可达到 $70 \%$ 和 $60 \%$, 并提供了粘叶杜鹃 亚组(subsect. Scabrifolia)内 2 个常见种人工杂交成 功的事例(张长芹等, 1998)。常绿杜鹃亚属中不同亚 组间通过人工杂交获得著名品种的例子当属喇叭 杜鹃 $(R$. discolor $) \times$ 火红杜鹃 $(R$. neriiflorum) 育成黄 色杜鹃品种“Bobolink’ (余树勋, 1992)。

Tom等(2007)提供了十分有参考价值的映山红 亚属分别与杜鹃亚属越桔杜鹃组、常绿杜鹃亚属和 羊蹶躅亚属的种间杂交结果。研究表明, 不同亚属 间的杂交组合及正、反交的杂交效果存在差异, 其 中羊蹶躅亚属 $\times$ 映山红亚属表现为明显的单向不 亲和(unilateral incompatibility), 并认为在合子前和 合子后均会出现明显的杂交障碍, 但也可能获得有 生活力或有胚拯救价值的杂交后代。这与张长芹等 (1998)有关杜鹃花不同亚属间种间杂交不育的结果 不尽一致。

Kenji等(2000, 2006)、Akihide和Kenichi (2004, 2006)、Akihide等(2006)、Kaori等(2008)也先后注意 到了单向不育(unilateral sterility)问题。Kenji等(2006) 以羊踯躅亚属的 $R$. japonicum f. flavum 为父本, 映山 红亚属的 $R$. eriocarpum以及其他 6 个种类作为母本, 选择高交配能力的花粉, 成功实现了上述两个亚属 的杂交, 并获得了生活力强的杂交后代, 但反向杂 交则不能成功; 而将同样组合产生的 $\mathrm{F}_{1}$ 代加倍后的 四倍体克服了 $\mathrm{F}_{1}$ 代的花粉不育。Kaori等(2008)用一 个映山红的四倍体人工加倍材料代替二倍体的映 山红作母本, 仍用羊踯躅亚属二倍体的 R. japonicum f. flavum作父本, 其交配结果克服了因塑性核 基因不亲和而引起的白化苗现象, 并认为种间的倍 性杂交效果好于种内倍性杂交。刘晓青等(2010)还 发现，杜鹃花品种间的正反交结实率也存在差异。

Nobuo等(2008)以常绿芳香为育种目标, 成功 获得了映山红亚属 $R$. nakaharae 和其他几个杂种同 羊蹊躅亚属 $R$. arborescens和 $R$. viscosum正反交组合
的亚属间杂种。并通过实验证明, 有生活力的杂种 后代中, 叶绿体基因来自羊蹶躅亚属种类。Akihide 和Kenichi (2004)研究了映山红亚属13个种与羊距 躅亚属间的杂交, 结果表明合子前不亲和表现在花 粉管生长受阻和不能进入胚珠; 合子后不育表现在 胚珠不发育、种子不发芽和幼苗死亡。在 22 个不亲 和的组合中, 合子前不亲和、合子后不亲和与发育 障碍的数量分别为 $15 、 6$ 和 1 , 并认为在亚属间存在 杂交不亲和的变化，而亲和性存在个体差异。

$\mathrm{Li}$ 等(2015)以常绿杜鹃亚属的牛皮杜鹃为母本 与杜鹃亚属的迎红杜鹃 (R. mucronulatum)、白花迎 红杜鹃 (R. mucronulatum f. album)、亚布力杜鹃杂交 有较高的亲和性，与母本的自然授粉坐果率无显著 差异, 但杂种苗生长势微弱, 呈白化状态, 有败育 迹象，经继代培养2-3次后，生长势得到一定的恢 复, 且分化率明显高于牛皮杜鹃种胚苗，但植株的 颜色仍是黄绿色。而反交时，坐果率明显降低，其 中与映山红亚属的大字杜鹃 (R. schlippenbachii)杂 交后不能坐果，但亚布力杜鹃 $\times$ 牛皮杜鹃反交时 的种胚萌发率为 $39.81 \%$ ，显著高于正交，而且种胚 苗生长健壮。

郑硕理等(2016)对涉及常绿杜鹃亚属(云锦杜 鹃、大白杜鹃、露珠杜鹃、蝶花杜鹃 (R. aberco$n$ wayi))、映山红亚属(映山红)和羊踯躅亚属(羊踯躅) 等3亚属的 6 个种、 22 个种间杂交组合开展了研究, 发现云锦杜鹃与露珠杜鹃正反交双向亲和，云锦杜 鹃分别与大白杜鹃、羊踯躅和映山红正交单向亲和, 大白杜鹃 $\times$ 露珠杜鹃单向亲和, 另外云锦杜鹃 $\times$ 蝶花杜鹃与大白杜鹃 $\times$ 蝶花杜鹃也表现为亲和, 并认为云锦杜鹃是作母本的好材料。耿兴敏等(2017) 分别以映山红和马银花作母本开展了部分种间杂 交实验，共涉及16个种，结果表明，映山红与同亚 属的满山红(R. mariesii)、大字杜鹃以及常绿杜鹃亚 属中的马紧杜鹃均有良好的亲和性，与杜鹃亚属的 粗柄杜鹃和基毛杜鹃表现为弱亲和; 而马银花只同 杜鹃亚属有鳞大花亚组的江西杜鹃 (R. kiangsiense) 有弱亲和, 而与同亚属的西施花(R. ellipticum)不亲和。

庄平(2018a，b，c)对杜鹃花属部分类群不同分 类等级间的杂交开展了系统的研究，通过200个种 间杂交组合的实验分析，获得了以下初步结果：(1) 对常绿杜鹃亚属内的 12 个亚组 23 种杜鹃花的 64 个 杂交组合研究表明(庄平, 2018a), 常绿杜鹃亚属内 
的异种杂交具有很高的可育性，在64个杂交组合中， 可育与高可育组合 56 个, 占 $87.5 \%$, 无弱可育等级; 不亲和与败育组合 8 个, 不能坐果、不能结实和结实 不发芽之比为 $3: 1: 4$, 初步推断同时存在合子前不 亲和与合子后败育; 与相应的自然授粉比较, 常绿 杜鹃亚属内杂交会不同程度地导致可育性降低, 但 有 15 个组内与组间杂交组合表现出某种”超亲和”现 象，尽管不能完全排除人工干预对于结实与可育性 的加强作用。常绿杜鹃亚属内不同种类间杂交存在 单向不育现象, 但未见双向不育。(2)对杜鹃亚属有 鳞大花亚组(subsect. Maddenia)、三花杜鹃亚组 (subsect. Triflora)、亮鳞杜鹃亚组及腋花杜鹃亚组 (subsect. Scabrifolia)等4亚组 10 个杜鹃花种类的 22 个杂交组合(其中18个数据完整组合)的可育性进行 了研究(庄平, 2018b)。结果显示, 实验所涉及的杜鹃 亚属不同亚组间及三花杜鹃亚组内杂交均比较困 难, 在 18 个数据完整组合中, 高可育与可育组合比 率明显偏低, 不可育比率高达 $55.6 \%$; 在 10 个不可 育或败育组合中, 不能坐果、不能结实和可结实而 种子不能发芽的数量分布为 $6: 1: 3$, 其不亲和或败 育发生的阶段可能涵盖了从合子前到合子后的整 个阶段; 亲本一方为多倍体的组合, 其可育率仅为 $41.6 \%$, 尤其是母本为多倍体时，比二倍体组合的 可育率(50.0\%)低且无高可育组合出现。这再次印证 了倍性是导致该亚属植物不同种类杂交不亲和、不 育与育性下降的重要原因, 但并非唯一原因。亚组 间杂交的可育率(16.7\%)明显低于亚组内(三花杜鹃 亚组内 $58.3 \%)$, 与相应的母本自然授粉结果相比, 杂交明显导致多数可育组合绿苗率比率和单位可 育种子数量比率的大幅度下降, 可能是双亲遗传差 异及多倍体亲本介入后所导致的杂交衰退(hybrid weakness)现象; 在多倍体作母本的情况下, 杂交单 向不育或非对称基因渐渗明显。

对常绿杜鹃亚属、杜鹃亚属、马银花亚属、映 山红亚属和羊蹶躅亚属间的杂交(庄平，2018c), 共 涉及5亚属、15亚组、32种、杂交组合118个。研究 表明，亚属间杂交的可育比例仅 $20.0 \%$ ，高、中、低 与不育比例为 $2: 16: 8: 92$, 可育水平与亚属及其 类群组合有关; 杜鹃亚属与马银花亚属等 4 个亚属 级组合杂交不可育; 亲本杂交组合方式对亚属间杂 交有不同程度的影响，一些类群组合有明显的向性， 即杂交正反交的方向。以杜鹃亚属作母本与常绿杜
鹃亚属云锦杜鹃亚组杂交的可育组合高于反交组 合, 而且在大王杜鹃、粘毛杜鹃( $R$. glischrum)、露 珠杜鹃和马㛜杜鹃所涉及的亚组间的杂交亦如此, 但与银叶杜鹃亚组(subsect. Argyrophylla)杂交则正 好相反。研究还发现12对单向可育组合，见于常绿 杜鹃亚属与杜鹃亚属等 4 类亚属级杂交组合中; 杜 鹃花属的亚属间杂交不亲和与败育现象明显，不可 育组合占 $80 \%$, 不能坐果是败育的主要表征, 所有 可育组合的绿苗率比值和单位种子量比值无一例 达到相应母本的自然授粉水平; 双亲的系统发育关 系对亚属间可交配性具有重要影响并与可育程度 呈正相关，染色体倍性也有一定的影响。有关研究 也为探索和认识杜鹃花属植物亚属间的系统发育 关系提供了新的证据。

另外, 过去被认为是同科近缘属的一些类群, 曾被作为属间杂交的例子。包括分布于北美洲东部 的山月桂属(Kalmia)、北半球温带到寒带的杜香属 (Ledum)和北美与东亚的璎珞杜鹃属(Menziesia)。如 Pierce (1974)报道了Kalmia latifolia $\times R$. williamsianum成功杂交; Kehr (1977)声称用Ledum groenlandium $\times R$. ‘Elizabeth' (著名杜鹃品种)育成了一个 属间杂交的新品种“Brilliant”。但Williams等(1990) 对此存疑，其原因在于他们观察到，上述杂交组合 情况下, 授体花粉的确能被柱头俘获并进入胚囊且 显现出受精，但种子无生活力。Koichi等(2005)用 Menziesia mulitflora与九州杜鹃(R. kiusianum)(映山 红组)互交, 并用前者作为母本分别与映山红组的 $R$. tashiroi和R. kaempferi杂交得到约10\%的绿色苗木, 其他为白化苗(Koichi et al，2005)。后又采用 PCR-RFLP法分析证明, 所有的白化与浅绿色后代 均含有杜鹃属的叶绿体DNA, 而绿色苗木中含有璎 珞杜鹃属的相应DNA。由此认为, 杜鹃属的塑性基 因与㫨珞属的核基因不亲和。当Menziesia mulitflora 作为母本时, 大多数后代有质体传递; 在两属的杂 交中，塑性基因不亲和是独立于ptDNA而遗传的 (Koichi et al, 2005)。而基于分子系统的研究结果表 明, Menziesia和Ledum应归入杜鹃花属中(Oetsch et $\mathrm{al}, 2005)$ 。可见以上情形并非真正属间杂交的例子。

\section{讨论}

\section{1 交配亲和性}

亲和性是杜鹃花属植物育性研究的核心问题。 
本文所讨论的亲和性包括了合子前与合子后的全 部时间段, 严格地说是亲和性(合子前)与可育性(合 子后)的统称(刘定富和薛永彪, 1997)。

(1)自交亲和性。杜鹃花属是自交亲和与自交不 亲和并存的类群(Williams et al, 1990; Rouse et al, 1993)。通常较早演化出来的类群其自交亲和比例更 高, 这可能对认识杜鹃花属植物自交特性的形成有 一定意义, 而且自交也可能不仅仅是杜鹃花物种对 环境的被动响应(庄平, 2017b)。通常认为自交不亲 和为致死基因所导致的合子后不亲和(Williams et al, 1990)，但鉴于自交不能坐果的比率可高达 $80 \%$ 以上, 这一论断值得商榷(庄平, 2018d, e), 人工授粉可以 增加自交结实率(刘晓青等, 2010)。

(2)杂交亲和性与系统演化关系。总的趋势是亲 缘关系越近, 其亲和性越高, 亲缘关系越远, 则亲 和性越低。如常绿杜鹃亚属、映山红亚属和越桔杜 鹃组内杂交亲和性较强, 而无鳞类与有鳞类亲和力 较弱(Tom et al, 2007)。庄平(2018e)的研究结果进一 步表明, 在亚属级之间的杂交中, 其亲和性表现为: 常绿杜鹃亚属内杂交 > 杜鹃亚属内杂交 > 常绿 杜鹃亚属 $\times$ 杜鹃亚属 $>$ 杜鹃亚属 $\times$ 映山红亚 属 > 常绿杜鹃亚属 $\times$ 映山红亚属 > 常绿杜鹃亚 属 $\times$ 羊蹶躅亚属 > 常绿杜鹃亚属 $\times$ 马银花亚 属 > 杜鹃亚属 $\times$ 羊蹊躅亚属; 而在亚组级杂交中, 银叶杜鹃亚组 $\times$ 同亚属的其他亚组 $>$ 云锦杜鹃 亚组内杂交 > 云锦杜鹃亚组 $\times$ 银叶杜鹃亚组 > 银叶杜鹃亚组 $\times$ 杜鹃亚属各组 $>$ 三花杜鹃亚组 内杂交 $>$ 云锦杜鹃亚组 $\times$ 同亚属其他亚组 $>$ 云 锦杜鹃亚组 $\times$ 杜鹃亚属各组 $>$ 常绿杜鹃亚属的 其他亚组 $\times$ 杜鹃亚属各组。以上结果说明杂交亲 和性与系统发育关系存在相关性, 不支持二者没有 关联的观点(耿兴敏等, 2017)。综合有关亚属间远缘 杂交的结果, 常绿杜鹃亚属与映山红亚属间的正反 交、映山红亚属与杜鹃亚属及常绿杜鹃与杜鹃亚属 (迎红杜鹃亚组subsect. Rhodorastrum)的正反交、映 山红亚属与羊踯躅的正交以及常绿杜鹃亚属与羊 蹶躅亚属的正交、马银花亚属与杜鹃亚属正交等均 表现出一定的亲和性。

(3)染色体倍性与杂交亲和性有关。二倍体之间 杂交亲和性较强, 杂交子代经加倍后可能提高生活 力。有研究表明映山红类群的人工加倍的四倍体材 料作母本、二倍体作父本比反交亲和性强(Kaori et al，2008)，但杜鹃花属内杂交亲本倍性的搭配方向 则正好相反, 其多倍体作母本的杂交亲和力反而较 低(庄平, 2018b)。

(4)杂交不亲和的发生阶段。作者对有关200个 杂交组合的研究也表明(庄平，2018d), 杜鹃花属种 间杂交的不育组合比例约为 $54.5 \%$ ，其不亲和与败 育包括不能坐果(Cab型)、坐果但不能形成种子( $\mathrm{Sab}$ 型)和能形成种子但不能发芽(Sng型)等3种情况，其 中 Cab与 Sab类型均可能是前合子期不亲和与后合 子期不亲和的复合表征, Sng型则可以肯定为合子 后种子发育阶段败育的情况, Cab : Sab : Sng = 81 : $13: 15$, 有关不育类型的分布与杜鹃花属植物亲本 类群及其分类与亲缘关系具有明显关联，从同一亚 组内、同一亚属内到不同亚属间杂交的不育类型的 分布呈 $\mathrm{Sng} \rightarrow \mathrm{Sab} \rightarrow \mathrm{Cab}$ 增加的趋势，杂交双亲分类 上亲缘关系越密切, Sng型的频度越高, 反之关系越 疏远, Cab型的频率越高，亚属间远缘杂交往往止于 Cab型。另外“杂种不活”为败育苗的表现形式之一, 败育程度也与亲本的亲缘关系有类似的关联，但映 山红分别与百合花杜鹃(R. liliiflorum)和毛肋杜鹃的 亚属间杂交未出现败育苗分布。

(5)单向不亲和是杜鹃花属植物杂交中较为普 遍的现象，也与双亲的系统关系与染色体倍性有 关。在杜鹃花杂交中, 羊蹶躅亚属 $\times$ 映山红亚属、 映山红亚属 $\times$ 越桔杜鹃组之间的杂交组合存在单 向不亲和现象(Kenji et al, 2000, 2006; Akihide \& Kenichi, 2004, 2006; Tom et al, 2007; Kaori et al, 2008); 笔者的实验进一步表明，在常绿杜鹃亚属内 杂交、杜鹃亚属内杂交、常绿杜鹃亚属 $\times$ 杜鹃亚 属及其他亚属间杂交也均存在单向不亲和现象，并 有依亲本亲缘关系疏远而加剧的趋势，与物种的倍 性也有关(庄平, 2018a, b, c)。

\section{2 向性}

向性指杂交亲本的搭配方式或方向，即正交和 反交对亲和性或可育性的响应(孟金陵, 1997)。在以 前的研究中, 杜鹃花杂交的正反交多有涉及, 研究 认为胞质不育和多倍化是引起单向不育的重要原 因(Akihide \& Kenichi, 2004, 2006; Kenji et al, 2006; Tom et al, 2007; Kaori et al, 2008)。笔者依据该属5 亚属、3组、12亚组、32种、33对正反交组合与自 交性质清楚的186个杂交组合，对有关向性问题进 行了初步总结(庄平, 2019)。结果表明，杜鹃花属植 
物种间杂交由双向可育 $\rightarrow$ 单向不育 $\rightarrow$ 双向不育的 比率变化可能与物种间的系统发育关系有关, 最早 分化的常绿杜鹃亚属内种间比分化较晚的杜鹃亚 属内种间易于杂交，且这两个亚属间杂交的可育比 率也高于其他亚属间的搭配。种间杂交单向不育通 常无固定的亲本搭配方向, 但常绿杜鹃亚属内、杜 鹃亚属内和映山红亚属 $\times$ 羊蹶躅亚属间的杂交搭 配表现出一定的倾向性, 即常绿杜鹃亚属的物种作 为母本杂交成功机会更高。种间杂交可育性与自交 特性不同的亲本搭配方式相关，可育性大小的趋势 为 $\mathrm{SC} \times \mathrm{SC}>\mathrm{SI} \times \mathrm{SC} \geq \mathrm{SC} \times \mathrm{SI}>\mathrm{SI} \times \mathrm{SI}, \mathrm{SI}$ 亲本的 介入会大幅度地增加种间杂交的不育比率。

\section{参考文献}

Akihide O, Kenichi S (2004) Cross incompatibility between Rhododendron seat. Tsutsusi species and Rhododendron japonicum (A. Gray) T. V. Suringar f. flavum Nakai. Journal of the Japanese Society for Horticultural Science, 73, 453-459.

Akihide O, Hiroshi I, Kenichi S (2006) Variation in crossability among Rhododendron japonicum f. flavum plants as pollen parents when crossed with evergreen species, $R$. eriocarpum. Journal of the Japanese Society for Horticultural Science, 75, 270-272.

Akihide O, Kenichi S (2006) Crossability of Kurume Azaleas as a seed parent for hybridizing with Rhododendron japonicum (A. Gray) J. V. Suringar f. flavum Nakai. Journal of the Japanese Society for Horticultural Science, 75, 191-198.

Akiko O, Ikumi D, Takashi S (2008) Bumblebee pollination and reproductive biology of Rhododendron semibarbatum (Ericaceae). Journal of Plant Research, 121, 319-327.

Akira SH (2010) Kinship between parents reduces offspring fitness in a natural population of Rhododendron brachycarpum. Annals of Botany, 105, 637-646.

Ammal EK (1950) Polyploidy in the genus Rhododendron. The Rhododendron Year Book, 5, 92-96.

Ammal EK, Enoch IC, Bridgwater M (1950) Chromosome numbers in species of Rhododendron. The Rhododendron Year Book, 5, 78-91.

Brown GK, Craven LA, Udovicic F, Ladiges PY (2006) Phylogeny of Rhododendron section Vireya (Ericaceae) base on two non-coding regions of cpDNA. Plant Systematics and Evolution, 257, 57-93.

Chamberlain DF, Hyam R, Argent G, Fairweather G, Walter KS (1996) The Genus Rhododendron, Its Classification and Synonymy. Royal Botanic Garden Edinburgh, Edinburgh.

Escaravage N, Wagner J (2004) Pollination effectiveness and pollen dispersal in a Rhododendron ferrugineum (Ericaceae) population. Plant Biology, 6, 606-615.

Fang MY, Fang RZ, He MY, Hu LZ, Yang HB (2005)
Rhododendron. In: Flora of China (eds Wu ZY, Raven PH, Hong DY), Vol. 14, pp. 83-87. Science Press, Beijing \& Missouri Botanical Garden Press, St. Louis.

Fang RZ, Min TL (1981) The influence of uplift of Himalayas on the floristic formation of genus Rhododendron. Acta Botanica Yunnanica, 3, 147-157. (in Chinese with English abstract) [方瑞征, 闵天禄 (1981) 喜玛拉雅山脉的隆升 对杜鹃属区系形成的影响. 云南植物研究, 3, 147-157.]

Fang RZ, Min TL (1995) The floristic study on the genus Rhododendron. Acta Botanica Yunnanica, 17, 359-379. (in Chinese with English abstract) [方瑞征，闵天禄 (1995) 杜 鹃属植物区系的研究. 云南植物研究, 17, 359-379.]

Gaku K (1993) Relationships between flowering time and fruit set of the entomophilous alpine shrub, Rhododendron aureum (Ericaceae), inhabiting snow patches. American Journal of Botany, 80, 1300-1304.

Gaku K, Akira SH, Yuka K (2011) Pollination efficiency of bumblebee queens and workers in the alpine shrub Rhododendron aureum. International Journal of Plant Sciences, 172, 70-77.

Gao LM, Zhang CQ, Li DZ, Wu D (2005) Chromosome numbers of Rhododendron subgen. Azaleastrum. Acta Botanica Yunnanica, 27, 433-436. (in Chinese with English abstract) [高连明, 张长芹, 李德铢, 吴丁 (2005) 杜鹃花属马银花 亚属一些种类染色体数目报道.云南植物研究, 27 , 433-436.]

Geng XM, Zhao HJ, Wu YQ, Zhang YM (2017) Cross- compatibility of wild Rhododendron and the effective evaluation indicators. Guihaia, 37, 979-988. (in Chinese with English abstract) [耿兴敏, 赵红娟, 吴影倩, 张月苗 (2017) 野生 杜鹃杂交亲和性及适宜的评价指标。广西植物，37, 979-988.]

Gillian KB, Lyn AC, Frank U, Pauline YL (2006) Phylogenetic relationship of Rhododendron section Vireya (Ericaceae) interred from the ITS nrDNA region. Australian Systematic Botany, 19, 329-342.

Goetsch L, Eckert AJ, Hall BD (2005) The molecular systematics of Rhododendron (Ericaceae): A phylogeny based upon RPB2 gene sequences. Systematic Botany, 30, 616-626.

Griffin CAM, Eckert CG (2003) Experimental analysis of biparental inbreeding in a self-fertilizing plant. Evolution, 57, 1513-1519.

Hirao AS, Kameyama Y, Ohara M, Isagi Y, Kudo G (2006) Seasonal changes in pollinator activities influence pollen dispersal and seed production of the alpine shrub Rhododendron aureum (Ericaceae). Molecular Ecology, 15, 1165-1173.

Huang CC, Hung KH, Hwang CC (2011) Genetic population structure of the alpine species Rhododendron pseudochrysanthum, sensu lato (Ericaceae) inferred from chloroplast and nuclear DNA. BMC Evolutionary Biology, 11, 108124. 
Huang ZH, Song YP, Huang SQ (2017) Evidence for passerine bird pollination in Rhododendron species. AoB Plant, 9, $1-10$.

Jose AM, Juan A, Fernando O (2002) Reproductive ecology of Rhododendron ponticum (Ericaceae) in relict Mediterranean populations. Botanical Journal of the Linnean Society, 140, 297-311.

Kaori S, Ozaki Y, Ureshino K, Miyajima I, Wakana A, Okubo H (2008) Interploid crossing overcomes plastome-nuclear genome incompatibility in intersubgeneric hybridization between evergreen and deciduous azaleas. Scientia Horticulturae, 115, 268-274.

Karlsson PS, Jacobson A (2001) Onset of reproduction in Rhododendron lapponicum shoots: The effect of shoot size, age, and nutrient status at two subarctic sites. Oikos, 94, 279-286.

Kehr AE (1977) Azaleodendron breeding. Journal of American Rhododendron Society, 31, 226-232.

Kenji U, Miyoko K, Ikuo M (2000) Factors of intersectional unilateral cross incompatibility between several evergreen azalea species and Rhododendron japonicum f. flavum. Journal of the Japanese Society for Horticultural Science, 69, 261-265.

Kenji U, Yoshiko T, Yuka T, Takeru Ii, Ikue M, Masaru A (2006) Cross compatibility of intersubgeneric hybrids of azaleas on backcross with several evergreen species. Journal of the Japanese Society for Horticultural Science, 75, 403-409.

Koichi K, Yuji K, Tomohisa Y, Shigeo N, Takashi H (2005) Plastid inheritance and plastome-genome incompatibility of intergeneric hybrids between Menziesia and Rhododendron. Journal of the Japanese Society for Horticultural Science, 74, 318-323.

Kurashige Y, Etoh JI, Handa T, Takayamagi K, Yukawa T (2001) Section relationships in genus Rhododendron (Ericaceae): Evidence from matK and trnK intron sequences. Plant Systematic Evolution, 228, 1-14.

Lan X, Zhang LH, Zhang JZ, Cui HX, Jiang CD, Shi L (2012) Research progress of Rhododendron breeding. Acta Horticulturae Sinica, 39, 1829-1838. (in Chinese with English abstract) [兰熙, 张乐华, 张金政, 崔红霞, 姜闯道, 石雷 (2012) 杜鹃花育种研究进展. 园艺学报, 39, 1829-1838.]

Levins R (1970) Extinction. In: Some Mathematical problems in Biology (ed. Gerstenhaber M), pp. 77-107. American Mathematical Society Rhode Island, Providence.

Li SH, Sun WB, Ma YP (2018) Current conservation status and reproductive biology of the giant tree Rhododendron in China. Nordic Journal of Botany, doi: 10.1111/njb.01999.

Li XS, Ba CY, Cao HN, Zong CG, Qu L, Zhang JZ (2015) Interspecific cross compatibility of Rhododendron in Changbai Mountain. Agricultural Science \& Techno, 16, 16171620.

Liu DF, Xue YB (1997) Plant self-incompatibility. In: Genetics of Plant Reproduction (ed. Meng JL), pp. 214-277. Science Press, Beijing. (in Chinese) [刘定富, 薛永彪 (1997) 植物 自交不亲和性, 214-277页. 见: 植物生殖遗传学(孟金陵 主编). 科学出版社, 北京.]

Liu XQ, Su JL, Li C, Liu XH (2010) Study on the fruitfulness of hybridization, selfing and open pollination of Rhododendron. Acta Agriculture Shanghai, 26, 145-148. (in Chinese with English abstract) [刘晓青, 苏家乐, 李畅, 刘晓宏 (2010) 杜鹃花自交、杂交及开放授粉结实性研究. 上海 农业学报, 26, 145-148.]

Liu YF, Xing M, Zhao W, Fan RY, Luo S, Chen X (2012) Genetic diversity analysis of Rhododendron aureum Georgi (Ericaceae) located on Changbai Mountain using ISSR and RAPD markers. Plant Systematic Evolution, 298, 921-930.

Ma YP, Zhang CQ, Zhang JL, Yang YB (2010) Natural hybridization between Rhododendron delavayi and $R$. cyanocarpum (Ericaceae), from morphological, molecular and reproductive evidence. Journal of Integrative Plant Biology, 52, 844-851.

Ma YP, Xie WJ, Sun WB, Marczewski T (2016) Strong reproductive isolation despite occasional hybridization between a widely distributed and a narrow endemic Rhododendron species. Scientific Reports, 6, 19146.

Meng JL (1997) Genetics of Plant Reproduction, pp. 296-357. Science Press, Beijing. (in Chinese) [孟金陵 (1997) 植物 生殖遗传学, 296-357页. 科学出版社, 北京.]

Milne RI, Terzioglu S, Abbott RJ (2003) A hybrid zone dominated by fertile $F_{1} s$ : Maintenance of species barriers in Rhododendron. Molecular Ecology, 12, 2719-2729.

Milne RI, Davies C, Prickett R, Inns LH (2010) Phylogeny of Rhododendron subgenus Hymenanthes based on chloroplast DNA markers: Between-lineage hybridisation during adaptive radiation? Plant Systematic Evolution, 285, 233-244.

Min TL, Fang RZ (1979) On the origin and geographic distribution of genus Rhododendron L. Acta Botanica Yunnanica, 1, 121-127. (in Chinese with English abstract) [闵天禄, 方瑞征 (1979) 杜鹃属Rhododendron L. 的地理 分布及起源问题的探讨. 云南植物研究, 1, 121-127.]

Min TL, Fang RZ (1990) The phylogeny and evolution of genus Rhododendron. Acta Botanica Yunnanica, 12, 353-365. (in Chinese with English abstract) [闵天禄, 方瑞 征 (1990) 杜鹃属的系统发育与进化. 云南植物研究, 12 , 353-365.]

Nathannel TW, Erin ED, Joseph BF, Stefan HG, David AM, Justin GS, Timothy MS, Sarah LR, Andrew GZ (2006) Pollinator limitation, autogamy and minimal inbreeding depression in insect-pollinated plants on a boreal island. American Midland Naturalist, 155, 19-38.

Ng SC, Corlett RT (2000) Comparative reproductive biology of the six species of Rhododendron (Ericaceae) in Hong Kong, South China. Canadian Journal of Botany, 78, 221-229.

Nobuo K, Daiki M, Akira N, Masaru A (2008) Attaining inter-subgeneric hybrids in fragrant azalea breeding and the 
inheritance of organelle DNA. Euphytica, 159, 67-72.

Oetsch LG, Eckert AJ, Hall BD (2005) The molecular systematics of Rhododendron (Ericaceae): A phylogeny based upon RPB2 gene sequences. Systematic Botany, 30, 616-626.

Palser BF, Rouse JL and Williams EG (1989) Coordinated timetables for megagametophyte development and pollen tube growth in Rhododendron nuttallii from anthesis to early postfertilization. American Journal of Botany, 76, 1167-1202.

Pierce L (1974) An unusual intergeneric cross. Journal of American Rhododendron Society, 28, 45-50.

Pornon A, Escaravage N, Boche TB (1997) Variation of reproductive traits in Rhododendron ferrugineum $\mathrm{L}$. (Ericaceae) population along a successional gradient. Plant Ecology, 130, 1-11.

Richard JA, Juliet KJ, Richard IM, Amanda CM (2003) Plant introduction, hybridization and gene flow. Philosophical Transactions of the Royal Society B: Biological Sciences, 358, 1123-1132.

Rouse JL, Knox RB, Williams EG (1993) Inter- and intraspecific pollinations involving Rhododendron species. Journal of American Rhododendron Society, 47, 23-28.

Ruth A, Kwiton J, George A (2000) Chromosome numbers of some tropical Rhdodendrons (Section Vireya). Edinburgh Journal of Botany, 57, 1-7.

Sax K (1930) Chromosome stability in the genus Rhododendron. American Journal of Botany, 17, 247-251.

Schepper SD, Leus L, Mertens M, Bockstaele EV, Loose MD, Debergh P, Heursel J (2001) Flow cytometric analysis of ploidy in Rhododendron (subgenus Tsutsusi). Hortscience, 36, 125-127.

Shrestha, N, Wang ZH, Su XY, Xu XT, Lyu L, Liu YP, Dimitrov D, Kennedy JD, Wang QG, Tang ZY, Feng XJ (2018) Global patterns of Rhododendron diversity: The role of evolutionary time and diversification rates. Global Ecology and Biogeography, 27, 913-924.

Song YP, Huang ZH, Huang SQ (2019) Pollen aggregation by viscin threads in Rhododendron varies with pollinator. New Phytologist, 221, 1150-1159.

Stout JC, Parnell JA, Arroyo J, Crowe TP (2006) Pollination ecology and seed production of Rhododendron ponticum in native and exotic habitats. Biodiversity and Conservation, 15, 755-777.

Tagane S, Hiramatsu M, Okubo H (2008) Hybridization and asymmetric introgression between Rhododendron eriocarpum and $R$. indicum on Yakushima Island, southwest Japan. Journal of Plant Research, 121, 387-395.

Tom E, Ellen DK, Johan VH, Jan DR, Erik VB (2007) Application of embryo rescue after interspecific crosses in the genus Rhododendron. Plant Cell, Tissue and Organ Culture, 89, 29-35.

Wang DY, Liu YJ, Bai YQ, Xie LJ (2012) The breeding research progress of Rhododendron plants. Journal of Anhui
Agriculture Science, 40, 15622-15625, 15627. (in Chinese with English abstract) [王定跃, 刘永金, 白宇清, 谢利娟 (2012) 杜鹃花属植物育种研究进展. 安徽农业科学, 40, 15622-15625, 15627.]

Williams EG, Rouse JL (1988) Lengths contribute to isolation of species in Rhododendron. Australian Journal of Botany, 36, 183-191.

Williams EG, Rouse JL, Palser BF, Knox RB (1990) Reproductive biology of rhododendron. Horticultural Reviews, 12, 1-67.

Wolf PG, Doche B, Gielly L, Taberlet P (2004) Genetic structure of Rhododendron ferrugineum at a wide range of spatial scale. Journal of Heredity, 95, 301-308.

Wu H, Yang XM, Shao HM, Wang F (2013) Germplasm resource base for rhododendron horticulture: Status, problems and countermeasures. Biodiversity Science, 21, 628-634. (in Chinese with English abstract) [吴荭, 杨雪梅, 邵慧敏, 王飞 (2013) 杜鹃花产业的种质资源基础: 现 状、问题与对策. 生物多样性, 21, 628-634.]

Yan LJ, Burgess KS, Milne R, Fu CN, Li DZ, Gao LM (2017) Asymmetrical natural hybridization varies among hybrid swarms between two diploid Rhododendron species. Annals of Botany, 120, 51-61.

Yan LJ, Burgess KS, Zheng W, Tao ZB, Li DZ, Gao LM (2018) Incomplete reproductive isolation between Rhododendron taxa enables hybrid formation and persistence. Journal of Integrative Plant Biology, 61, 433-448.

Yu SX (1992) Rhododendron, pp. 100-113. Jindun Press, Beijing. (in Chinese) [余树勋 (1992) 杜鹃花, 100-113页. 金盾出版社, 北京.]

Zha HG, Milne RI, Sun H (2010) Asymmetric hybridization in Rhododendron agastum: A hybrid taxon comprising mainly $\mathrm{F}_{1} \mathrm{~s}$ in Yunnan, China. Annals of Botany,105, 89-100.

Zhang CQ, Feng BJ, Lü YL (1998) Hybridization study of the genus Rhododendron. Acta Botanica Yunnanica, 20, 94-96. (in Chinese with English abstract) [张长芹, 冯宝钧, 吕元 林 (1998) 杜鹃花属植物的杂交研究. 云南植物研究, 20, 94-96.]

Zhang CQ, Luo JF, Feng BJ (2002) New rhododendron hybrid-'Zhaohui' and 'Hongyun'. Acta Horticulturae Sinica, 29, 296. (in Chinese with English abstract) [张长芹, 罗吉 凤, 冯宝均 (2002) 杜鹃花新品种“朝晖”和 “红晕”. 园艺 学报, 29, 296.]

Zhang JL, Zhang CQ, Wu ZQ, Qiao Q (2007) The potential roles of interspecific pollination in natural hybridization of Rhododendron species in Yunnan, China. Biodiversity Science, 15, 658-665. (in Chinese with English abstract) [张 敬丽, 张长芹, 吴之坤, 乔琴 (2007) 探讨种间传粉在杜 鹃花属自然杂交物种形成中的作用. 生物多样性, 15, 658-665.]

Zhang JL, Zhang CQ, Gao LM, Yang JB, Li HT (2007) Natural hybridization origin of Rhododendron agastum (Ericaceae) in Yunnan, China: Inferred from morphological and molecular 
evidence. Journal of Plant Research, 120, 457-463.

Zheng SL, Yi CR, Liu Q, Zhang JL (2016) Primary study on hybridization breeding among several Rhododendron species in Yunnan Province. Journal of Yunnan Agricultural University (Natural Science), 31, 1052-1057. (in Chinese with English abstract) [郑硕理, 易陈然, 刘巧, 张敬丽 (2016) 云南几种杜鹃杂交育种初探. 云南农业大学学报 (自然科学版), 31, 1052-1057.]

Zhuang P (2012) Discussion on the Rhododendron geographical distribution types and their cause of formation in China. Guihaia, 32, 150-156. (in Chinese with English abstract) [庄 平 (2012) 中国杜鹃花属植物地理分布型及其成因的探 讨. 广西植物, 32, 150-156.]

Zhuang P, Wang F, Shao HM (2013) Comparative study on Rhododendron and their distribution in W-Sichuan and SE-Tibet. Guihaia, 33, 791-797. (in Chinese with English abstract) [庄平, 王飞, 邵慧敏 (2013) 川西与藏东南地区 杜鹃花属植物及其分布的比较研究. 广西植物, 33, 791-797.]

Zhuang P (2017a) Natural pollination of 37 Rhododendron species under ex situ conservation. Guihaia, 37, 947-958. (in Chinese with English abstract) [庄平 (2017a) 37种杜鹃花 属植物在迁地保育下的自然授粉研究. 广西植物, 37, 947-958.]

Zhuang P (2017b) Self-fertilization of 32 Rhododendron species under ex situ conservation. Guihaia, 37, 959-968. (in Chinese with English abstract) [庄平 (2017b) 32种杜鹃花 属植物在迁地保育条件下的自交研究. 广西植物, 37, 959-968.]
Zhuang P (2018a) Cross fertility of intra-subgen. Hymenanthes of 23 Rhododendron species. Guihaia, 38, 1545-1557. (in Chinese with English abstract) [庄平 (2018a) 23种常绿杜 鹃亚属植物种间杂交的可育性研究. 广西植物, 38, 1545-1557.]

Zhuang P (2018b) Cross fertility of intra-subgen. Rhododendron of 10 Rhododendron species. Guihaia, 38, 1558-1565. (in Chinese with English abstract) [庄平 (2018b) 10 种杜鹃亚属植物种间杂交的可育性研究. 广西 植物, 38, 1558-1565.]

Zhuang P (2018c) Cross fertility of inter-subgenera of 32 Rhododendron species. Guihaia, 38, 1566-1580. (in Chinese with English abstract) [庄平 (2018c) 32种杜鹃花属植物亚 属间杂交的可育性研究. 广西植物, 38, 1566-1580.]

Zhuang P (2018d) Distribution of hybrid incompatibility and sterility of Rhododendron. Guihaia. 38, 1581-1587. (in Chinese with English abstract) [庄平 (2018d) 杜鹃花属植物 杂交不亲和与败育分布研究. 广西植物, 38, 1581-1587.]

Zhuang P (2018e) Crossability and its characteristics of Rhododendron. Guihaia. 38, 1588-1594. (in Chinese with English abstract) [庄平 (2018e) 杜鹃花属植物种间可交 配性及其特点. 广西植物, 38, 1588-1594.]

Zhuang P (2019) Preliminary study on the direction of inter-specific cross of Rhododendron. Guihaia, doi: 10.11931/guihaia.gxzw20183003. (in Chinese with English abstract) [庄平 (2019) 杜鹃花属植物种间杂交向性的初 步研究. 广西植物, doi: 10.11931/guihaia.gxzw20183003.]

(责任编委：高连明 责任编辑：黄祥忠) 